\title{
Starch Films Added of Açaí Pulp (Euterpe oleracea Martius)
}

\author{
Kênia Letícia Ferreira Pessanha ${ }^{1^{*}}$, Mônica Guimarães Farias ${ }^{1}$, Carlos Wanderlei Piler \\ Carvalho $^{2}$, Ronoel Luiz de Oliveira Godoy ${ }^{2}$. \\ ${ }^{1}$ Universidade Federal Rural do Rio de Janeiro - Universidade Federal Rural do Rio de Janeiro - Instituto de \\ Tecnologia Seropedica, RJ, Brazil; ${ }^{2}$ Embrapa Food Technology, Rio de Janeiro, Brazil
}

\begin{abstract}
Edible films are an alternative to synthetic materials used for packaging foods. The aim of this study was to develop and characterize films made from cassava starch, freeze-dried acai and glycerol. The films were characterized for thickness, water vapor permeability, water solubility, anthocyanins, antioxidant capacity and mechanical properties. The results indicated a rich edible film in anthocyanins with considerable antioxidant capacity (150.70 micromol Trolox), which can extend the commercial validity of the packaged food and meets the growing demand for biodegradable packaging that tends to reduce the environmental impact. The addition results in a significant effect on the polymer matrix reducing the water solubility and water activity. The elongation test at rupture reported to be $17.738 \%$, indicating that addition of pulp increased film flexibility.
\end{abstract}

Keywords: Active packaging, biodegradable, anthocyanins, ABTS, ORAC.

*Author for correspondence: kf.pessanha@ hotmail.com 


\section{INTRODUCTION}

Plastic food packaging is developed from polymers derived from petroleum. Despite their low cost and high mechanical resistance, they are not biodegradable ${ }^{1,2}$, taking around 400 years to decompose and the incorrect disposal is responsible for environment degradation and death of thousands of marineanimals ${ }^{3}$. In addition, such materials can cause harm to consumer's health such as liver and gestation damage besides being carcinogenic, once most of the food packaging is produced from polyvinyl chloride (PVC), the second most widely used thermoplastic in the world, developed from the vinyl chloride monomer and added with organic plasticizers ${ }^{4}$. It is known that petroleum based polymers, when heated, release volatile compounds that are toxic ${ }^{5}$ and when used for packing fatty foods, plasticizers tend to migrate into the food due to structural similarity to lipids ${ }^{4,6,7}$.

In an attempt to reduce that problem, new materials have been studied with the aim of forming biodegradable films capable of maintaining food quality and prolonging their commercial validity ${ }^{8}$, but not causing harm to consumer's health, since most of these materials are considered "generally recognized as safe" (GRAS) ${ }^{9}$. Thus, starch was one of the first polysaccharides studied for the formation of films and it is widely available and has a low $\cos ^{10}$; Among the sources of starch studied, cassava is the second most used for this purpose ${ }^{11}$.

Packagings added with edible natural compounds can provide interesting gas barrier properties $^{12}$, and result in films with added value, by increasing the commercial validity of the food. In addition, they can have the potential benefit of being added of bioactives compounds in the diet ${ }^{13}$. The Açaí fruits are produced by a palm tree found in Brazil, Euterpe Oleracea Martius, that have substantial phenolic compounds content, which can be used to increase the shelf life of foods due to the high antioxidant content and high concentration of anthocyanins ${ }^{14}$. Açaí is considered a 'superfruit' and contains anthocyanin content higher than fruits such as blackberry ${ }^{15}$. This property is interesting for preparation of functional films, since anthocyanins promote the prevention of auto-oxidation and lipid peroxidation in biological systems ${ }^{16}$.

There are no reports on cassava starch films added with açaí in the scientific literature until now. Another relevant aspect of the current literature is that antioxidant capacity of the starch films added of fruit sources has not been studied yet, therefore requires investigation. The objective of this work was to develop and to characterize plasticized glycerol cassava starch films added of lyophilized açaí pulp.

\section{MATERIALS AND METHODS}

Lyophilized açaí was donated by Liotécnica (São Paulo, Brazil); cassava starch, also called in Brazil as "polvilho doce", was purchased from a local market (Yoki Alimentos, São Paulo, Brazil); glycerol P.A. (Fine Chemistry, Duque de Caxias, RJ); citric acid anhydrous P.A.- A.C.S. (Synth, Diadema - SP) and distilled water were used in the elaboration of films.

\section{Preparation of Sample by Ultrassom}

In order to reduce the particle size distribution of lyophilized açaí particulate, an ultrasound was used ${ }^{17} .6 \mathrm{~g}$ of Açaí dissolved in $390 \mathrm{~mL}$ of distilled water was added with $6 \mathrm{~mL}$ of $3 \%$ citric acid solution. After solubilization, the solution was submitted to a sonifier ultrasound of $450 \mathrm{~W}$ (Branson Digital, Danbury, USA) at $25 \mathrm{kHz}$ in three amplitudes (12, 25 and 50\%) for $5 \mathrm{~min}$, pulse off of $5 \mathrm{~s}$ and pulse on of $2 \mathrm{~s}$. 


\section{Quantification of Anthocyanins by High Performance Liquid Chromatography (HPLC)}

The quantification of anthocyanins (QA) by HPLC in the samples of non sonicated lyophilized açaí and lyophilized açaí submitted to sonication was performed on anexternal standardized chromatograph model 2695 (Waters Alliance, Milford, USA), on a $4.6 \times 100 \mathrm{~mm}$ and $2.4 \mu \mathrm{m}$ (Thermo ${ }^{\circledR}$, Waltham- Massachusetts, USA) column, mobile gradient acetonitrile phase and $5 \%$ formic acid solution, $1.0 \mathrm{~mL} / \mathrm{min} ; 40{ }^{\circ} \mathrm{C}$ injector temperature, UV detector PDA 2996 Waters $(520 \mathrm{~nm})$; Injection volume 20 $\mu \mathrm{L}$ and run time $20 \mathrm{~min}^{18}$, according to the methodology described by Santiago ${ }^{19}$. The analysis was performed in triplicate.

\section{Particle Size Distribution}

The particle size distribution was determined by the laser diffraction S3500 (Microtrac Inc., Montgomery Ville, USA), following the methodology described by the ISO $13320-1^{20}$ and the principle of light scattering technique in the measurement of the laser diffraction angles and their relation with the diameter of the particle ${ }^{21}$. The analysis was conducted in triplicate where each aliquot was taken from a $60 \%$ aqueous solution of lyophilized açai. For each replicate, three cycles were performed. The distilled water was used as the dispersant/ carrier fluid and the refractive index of the starch (1.38) was adopted for calculations performed by the system.

\section{Antioxidizing Capacity}

The determination of the antioxidant capacity was performed by two different methods: ABTS ([2,2'-azino-bis (3-ethylbenzothiazolin) 6-sulphonic acid]) and ORAC (Oxygen Radical Absorbance Capacity), according to Rufino et al. ${ }^{22}$ and Zuleta et al. ${ }^{23}$, respectively. Samples were prepared for analysis according to the protocol of preparation described by $\mathrm{Re}$ et $\mathrm{al}^{24}$.

\section{Film Preparation}

Cassava films were prepared following the casting technique described by Farias et $\mathrm{a}^{8}$ using a film-forming solution at $4 \%$ starch and glycerol content of $23.7 \%$ dry starch. For the preparation of cassava starch films added of açaí, prior to the process, the lyophilized was sonicated acai (better condition selected) at concentration of $34.43 \%$. For both films, the film-forming solution was produced by using a Viscoamylograph N182506 (Brabender, Duisburg, Germany) under controlled conditions of shear and temperature. The heating cycle regime was heating up to $90{ }^{\circ} \mathrm{C}$ at a heating rate of 2 ${ }^{\circ} \mathrm{C} / \mathrm{min}$, keeping at this temperature for $10 \mathrm{~min}$ and cooling down to $50{ }^{\circ} \mathrm{C}$. The solution was poured into $142 \mathrm{~mm}$ plexi-glass dishes and dried in a fan oven at $30{ }^{\circ} \mathrm{C}$ $( \pm 5)$ for $24 \mathrm{~h}$. After drying the films were manually removed from the plates and stored at $52.9 \%$ relative humidity chambers, under vacuum until further analysis.

\section{Sample Preparation For Quantification of Anthocyanins and Antioxidant Capacity of the Films}

Due to film plasticity, liquid nitrogen was used in an A11 basic S32 knife mill (IKA, Staufen, Germany) in order to increase rigidity and facilitate the milling. As finer particles was required by the analyses, $5 \mathrm{~min}$ manual maceration was required followed by sieving at $150 \mu \mathrm{m}$ aperture size to obtain obtain fine particles. 


\section{Quantification of Anthocyanins From Films by HPLC}

$0.4 \mathrm{~g}$ of the powder obtained in item 2.6 was added with $400 \mu \mathrm{L}$ of distilled water remaining in repose for $10 \mathrm{~min}$ and extraction was carried out. An analysis was performed as described in item 2.2.

\section{Antioxidant Capacity (AC) From Films by ABTS and ORAC}

$0.5 \mathrm{~g}$ of the powder obtained in item 2.6 was submitted to AC extraction and analysis as described in item 2.4 .

\section{Film Thickness}

The thickness was determined in triplicate ${ }^{25}$, by direct reading in digital micrometer IP 54 (Fowler, Newton, USA), with a sensitivity of $\pm 0.001 \mathrm{~mm}$, measured at five random points for each film.

\section{Water Solubility}

$20 \mathrm{~mm}$ diameter films were weighed and placedin to a beaker with $50 \mathrm{~mL}$ of distilled water ${ }^{26}$. The system was kept under slow stirring in a Dubnoff NT 232 shaker bath (Piracicaba, Brazil) at $25^{\circ} \mathrm{C}$ for $24 \mathrm{~h}$. Then, the samples were dried in an oven at 105 ${ }^{\circ} \mathrm{C}$ for $24 \mathrm{~h}$. The result was calculated by the difference between the final (after solubilization and drying) and initial weights, and expressed as a percentage of dry solubilized material. The analysis was performed in triplicate.

\section{Water Vapor Permeability (PVA)}

Water vapor permeability was determined by gravimetry method according to ASTM (American Society for Testing and Material), modified E96-80 $0^{27}$ at $25{ }^{\circ} \mathrm{C}^{28}$. Circular films of $40 \mathrm{~mm}$ diameter were placedin permeation containers with distilled water. Containers were desiccated with blue silica gel to ensure a water gradient in the system, the whole being stored in a BOD incubator (Hydrosan, Belo Horizonte, Brazil) at $25{ }^{\circ} \mathrm{C}$ and $53 \%$ relative humidity for nine days with daily weight monitoring ${ }^{29}$.

\section{Water Activity}

The water activity (WA) was determined in triplicate by direct reading on the AquaLab Lite 2T (Decagon Devices Inc., Pullman, USA), at $25^{\circ} \mathrm{C}$. The samples were dimensioned in a circular format of $35 \mathrm{~mm}$ in diameter and placed in the capsules of the equipment.

\section{Mechanical Properties}

Determination of deformation tests and elasticity modulus followed the standard method proposed by ASTM ${ }^{30}$, D 828-95a, using the Texture Analyzer TA XT Plus (Stable Micro systems, Surrey, England) fitted with a tensile grip probe. A total of 14 replicates were performed for each assay, with specimens sized 50 x $15 \mathrm{~mm}$. It was set a distance of $30 \mathrm{~mm}$ between the grips and the test was conducted at a speed of 1 $\mathrm{mm} / \mathrm{s}$. The stress at the rupture was determined by the relationship between force and area of the initial cross section of the film. The modulus of elasticity in the linear 
region of the plot of the stress curve as a function of the strain and the strain at the break followed the equation 1 :

$\mathrm{R}=\mathrm{L} .100 / \mathrm{Ci}$

(1)

(where $\mathrm{R}$ is the elongation at break expressed in \%; $\mathrm{L}$ is the distance at the moment of rupture expressed in $\mathrm{mm}$ and $\mathrm{Ci}$ is the initial sample length in $\mathrm{mm}$ ).

\section{Statistical Analysis}

The results of each parameter were submitted to analysis of variance (ANOVA) and Tukey test with 95\% confidence using XLSTAT 2015 6.1 (Microsoft, Redmond, Washington, USA).

\section{RESULTS AND DISCUSSIONS}

\section{Ultrasound and Analysis of Açai Particle Size}

The three amplitudes used in the ultrasound significantly reduced the size of the açai particles $(\mathrm{P}<0.05)$. The use of ultrasound for $5 \mathrm{~min}$ at $50 \%$ amplitude was the most effective in reducing particle size, indicating an average D90 of $79.59 \pm 8.9 \mu \mathrm{m}$, whereas the non-sonicated lyophilized açai presented a D90 of $221.6 \mu \mathrm{m}$, followed by the açai subjected to $25 \%$ amplitude which showed D90 of $102.5 \pm 3,2^{\mathrm{b}} \mu \mathrm{m}$ and at $12 \%$ amplitude with D90 of $162.6 \pm 16,3^{\mathrm{c}} \mu \mathrm{m}$.

\section{Quantification of Açaí Anthocyanins.}

The lyophilized açai showed $311.46 \mathrm{mg} / 100 \mathrm{~g}$ of anthocyanins. After sonication at 12,25 and 50\% amplitudes, the values found were: $295.77 \pm 33.3 \mathrm{mg} / 100 \mathrm{~g}, 279.08 \pm$ $10.7 \mathrm{mg} / 100 \mathrm{~g}$ and $182.22 \pm 32.3 \mathrm{mg} / 100 \mathrm{~g}$, respectively. The higher anthocyanin degradation observed after sonication at 50\% amplitude could be attributed to sonolysis, which may lead to its hydrolysis in water molecules, causing the production of free radicals and consequent oxidation-reduction reaction of anthocyanin molecules ${ }^{31}$.

The majority of anthocyanins cyanidin-3-O-glycoside and cyanidin-3-O-rutenoside are displayed Figure 1 and reported in the literature ${ }^{32,33}$. The presence of anthocyanins is responsible for reducing the production of reactive oxygen species, which may lead to diseases such as diabetes, neurological damage, endothelial dysfunction and cardiovascular diseases by preventing the oxidation of low density lipoproteins. Anthocianins are also known to present anticarcinogenic, anti-inflammatory and antimicrobial properties ${ }^{34}$ 


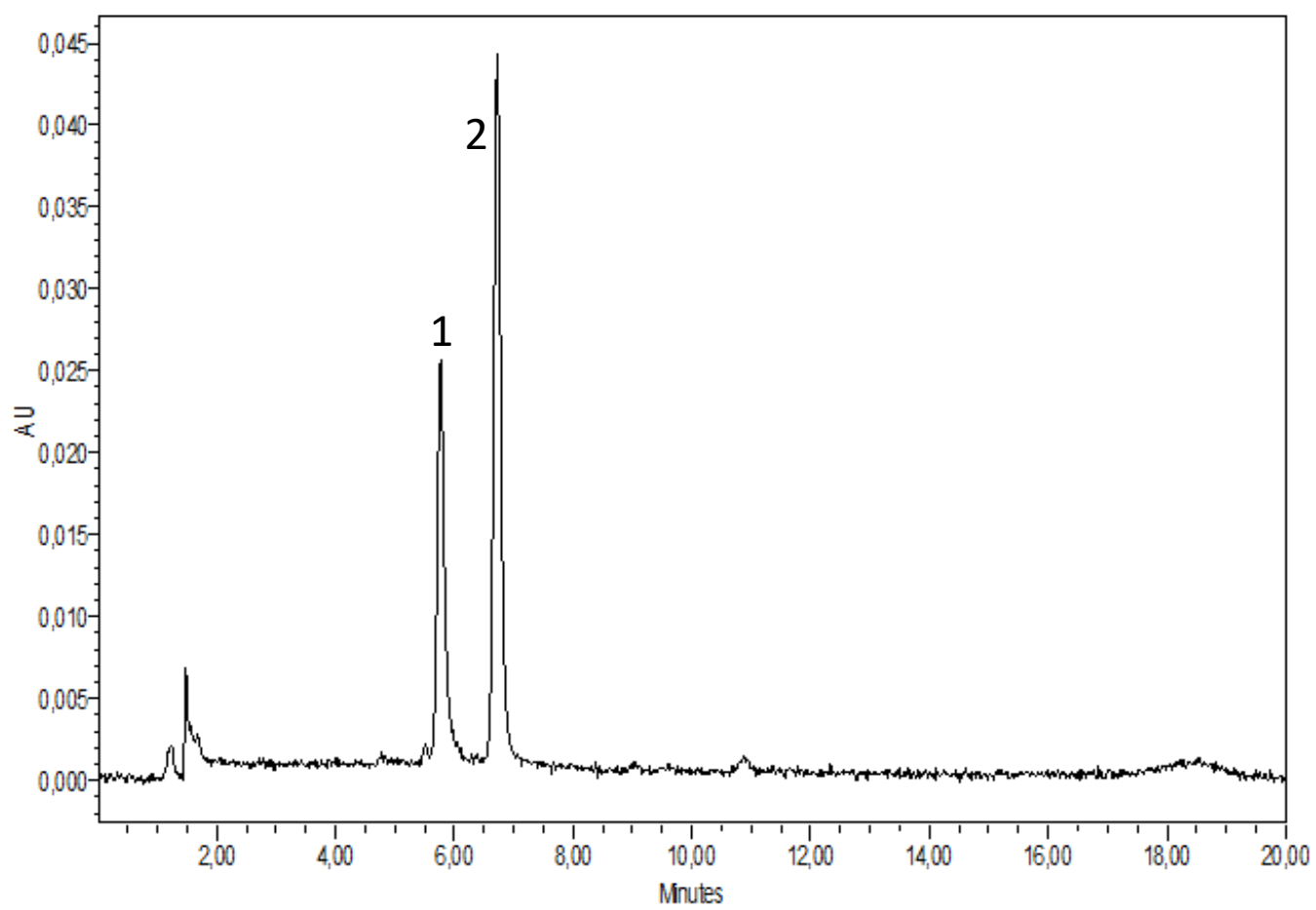

Figure 1. Chromatogram obtained in the UV region visible at $520 \mathrm{~nm}$ which reproduces the profile of the anthocyanins from the freeze-dried açaí anthocyanin extract. The main anthocyanin compounds are whon in the graph: (1) cyanidin-3-O-glucoside and second peak (2) peak cyanidin-3-O-rutenoside, with retention time of 5.7 min and $6.6 \mathrm{~min}$, respectively.

Although sonication has reduced anthocyanin content of lyophilized powder, these values found were are still higher than those found in the literature for commercial açaí pulps found in the Brazilian market, with values ranging from $157.70 \mathrm{mg} / 100 \mathrm{~g}$ to $201.44 \mathrm{mg} / 100 \mathrm{~g}^{35}$.

High storage periods ${ }^{36}$ even at low temperatures ${ }^{37}$ and the application of conservation processes in açaí fruits can also reduce bioactive compounds, however, they are essential for their microbiological safety ${ }^{38}$. Another factor that can directly interfere in the concentration of these compounds is the degree of maturation of the fruit, since there is a direct relationship between maturation and anthocyanin content ${ }^{39}$.

The difference between the results for the lyophilized açai and the in natura pulp can be attributed to the lyophilization effect in concentrating the samples ${ }^{40}$. However, Gouvêa ${ }^{41}$ found lower values than commercial pulps of frozen and freeze-dried açaí in the laboratory $(48.2 \mathrm{mg} / \mathrm{g}$ ), indicating that such reduction was probably related to the process performed by the industry that goes from harvesting to storage.

\section{Antioxidant Capacity of Lyophilized Açai Pulp: ABTS and ORAC}

The lyophilized pulp presented values of AC per ABTS of 208.02 $\pm 8.6 \mu$ mol Trolox / $\mathrm{g}$ and by ORAC $568.79 \pm 9.1 \mu \mathrm{mol}$ Trolox / g. These results are superior than those found in studies with fresh açaí pulps. Cruz ${ }^{42}$ found $36.6 \mu \mathrm{mol}$ Trolox / $\mathrm{g}$ for açaí pulp by ABTS, where fresh fruits were pulped for the study. Malcher ${ }^{35}$ analysis of açaí pulps harvested at different locations, with different planting techniques and at different times of the year, found the highest antioxidant activity by ABTS for one of the ten pulps analyzed (421.37 $\mu$ mol Trolox / g), with açaí harvested in high season 
and cultivated with minimal impact. Schauss et al. ${ }^{43}$ obtained higher ORAC (1027 $\mu \mathrm{mol}$ Trolox) results for fruits harvested and lyophilized specifically for the analysis, under storage conditions of $-20^{\circ} \mathrm{C}$, which allows greater preservation of anthocyanins, and may justify the difference against the result obtained in this work.

\section{Evaluations of Elaborated Films: Optical Aspects and Thickness}

The films presented a color compatible surface with the fruit (Fig. 2), indicating that the processing did not change abruptly the chromophore of the anthocyanins, the flavilcation.

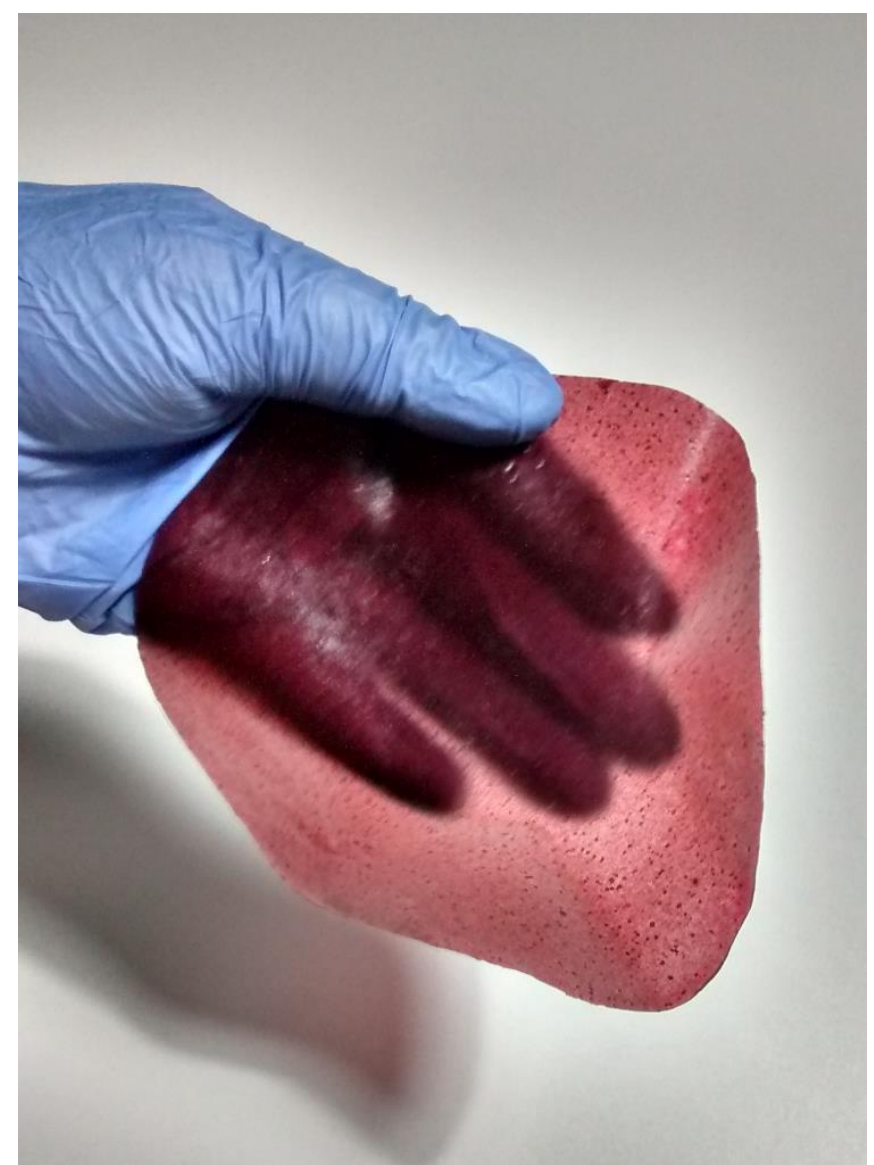

Figure 2. Visual aspect of cassava starch film added of lyophilized açaí and glycerol.

The thickness of the acai films varied from 0.162 to $0.175 \mathrm{~mm}$, according to the point where the measure was taken, whereas the control filmswas much more homogenous varying from 0.091 to $0.093 \mathrm{~mm}$. The addition of açaí significantly increased the thickness of the films ( $\mathrm{p}<0.0001$ ). Preliminary tests showed a considerable increase in surface roughness with a consequent increase in thickness, which led to the use of ultrasound that reduced the size of açai particles and increased homogeneity. The average sonication (25\%) was chosen to reconcile particle size and the presence of anthocyanins, since particle reduction by ultrasound also reduced anthocyanin content. These values are close to those found in cassava starch films added of lyophilized acerola pulp from 0.121 to $0.158 \mathrm{~mm}$. Films of cassava starch added of mango pulp and tea grass, the values of thickness ranged from 0.111 to $0.125 \mathrm{~mm}^{44}$, whereas açaí and pectin films added with essential oils, thickness range was wider, ranging from 
0.104 to $0.201 \mathrm{~mm}$. In the later, thickness increased with the addition of açaí pulp, which was similar to the result found in this work.

\section{Quantification of Anthocyanins (QA) in Films}

The content of anthocyanins in the film was $21.59 \pm 3.62 \mathrm{mg} / 100 \mathrm{~g}$. Although the result represents $10 \%$ of the anthocyanin content of the lyophilized açaí, it is still higher than the amount found in some commercial açaí pulps ${ }^{45}$. It is worth to note low concentration of lyophilized acai utilized in the film preparation $(34.43 \%)$, also thefilm development and drying may have contributed to certain anthocianin loss. This result shows the relevant contribution of acai anthocianin that was considerably preserved after all these processes.

Anthocyanins have the ability to establish hydrogen bonds due to the presence of hydroxyls in their chemical structure ${ }^{46,47}$, the same occuring with $\operatorname{starch}^{48}$. Due to this characteristic, anthocyanins are believed to have bound starch molecules by means of hydrogen bonds, which justifies the use of small amounts of water prior to solvent extraction, so that such molecules could be extracted. This fact is important given the instability of anthocyanins to many factors, so the entrapment of anthocyanins would probably allow greater preservation within the polymer matrix until its use. As the film can be ingested, it couldbe used as a vehicle for nutritional compounds, being classified as active packaging 8 .

The consumption of anthocyanins is variable. In the USA, it is estimated to be from 3 to $215 \mathrm{mg} /$ day $^{49}$ and the recommended daily dose is from 180 to $215 \mathrm{mg}$ / day, which is higher than the recommended dose for other flavonoids ${ }^{50}$. Therefore, the ingestion of two acai-starch films per day would represent approximately $20 \%$ of the estimated daily dose of anthocyanins, which is higher than the current dose. COOKE et al. ${ }^{51}$ and TSUDA et al. ${ }^{52}$ reported the benefits of anthocyanin due to the possibility of suppression and prevention of diseases.

\section{Antioxidant Capacity}

The antioxidante capacity (AC) of the films by ABTS and ORAC was $34.38 \pm 4.6$ $\mu \mathrm{mol}$ Trolox and $150.70 \pm 5.8 \mu \mathrm{mol}$ Trolox, respectively. It was observed that açaí film could keep $20 \%$ of antioxidant capacity, when quantified by the ORAC method, however it is worth to a note a considerable dilution of the açái with other components present in the açaí film such us starch, water, glycerol and citric acid. Despite dilution, açaí film showed higher antioxidant capacity than commercial frozen açai pulps (data not shown) and fresh fruits, such as strawberry $(20.6 \mu \mathrm{mol} \text { Trolox / g })^{53}$ and blueberry $(29.20 \mu \mathrm{mol}$ Trolox / g) 37 .

Concerning the differences of the results of ORAC and ABTS, the former is more sensitive and specific for the evaluation of anthocyanins, since it is able to respond to a greater number of antioxidant compounds than other test methods ${ }^{54}$. Silva et al. ${ }^{55}$ corroborated this assertion, since they compared the methods of ORAC and TEAC in plant analysis, and concluded that the ORAC method measured the CA of compounds that were not observed with the TEAC method. Cerezo et al. ${ }^{56}$ found that the ORAC and FRAP assays showed $32.61 \%$ and $17.58 \%$, respectively, for strawberry puree samples.

\section{Water Activity}

The WA for the açaí films ranged from 0.52 to 0.53 , compared to the control films 0.55 to 0.56 . Results similar to those found in the literature for mango puree $(0.52)^{57}$ and films for cassava starch films and lyophilized acerola pulp (0.50 to 0.54$)^{58}$. 
Statistical analysis indicated that the addition of the açai caused a significant reduction ( $\mathrm{P}<0.05)$ of the WA of the film, resulting in a material with a lower propensity for microbial activity and a greater chance of preservation of the anthocyanins in the matrix $^{36}$. Although the açaí had a high WA (0.92\%), the use of the lyophilized fruit allowed a reduction in this parameter, as well as the time / temperature binomial used in the drying of the films.

\section{Water Vapor Permeability of Films}

The water vapor permeability (WVP) ranged from 0.36 to $0.40 \mathrm{gmm} / \mathrm{m} 2 \mathrm{hkPa}$ for the açai film and from 0.34 to $0.35 \mathrm{~g} \mathrm{~mm} \mathrm{~h}^{-1} \mathrm{~m}^{-2} \mathrm{kPa}^{1}$ for the control film. The addition of açaí increased the WVP (P> 0.05), which can be explained by an increase of thickness, since greater thickness directly increasea $\mathrm{WVP}^{59}$. It was also observed in some oat starch films produced with varied plasticizers ${ }^{60}$. Starch films developed with hydrophilic materials present positive relationship between thickness and WVP, due to the interaction of water with the polymer matrix leading to structural changes caused by swelling of the hydrophilic matrix. This affects the film structure causing internal stresses that affects water permeation ${ }_{-}^{60}$.

WVP values were close to those found for cassava starch and soy protein ${ }^{29}$ films and for cassava starch and acerola pulp films ${ }^{8}$. For the pectin and açaí pulp films, the WVP was higher $(3.562 \mathrm{gmm} / \mathrm{m} 2 \mathrm{hkPa}) 13$. Studies report the reduction of WVP with the reduction of the added pulp content, which promotes a better interaction between the fibers of the pulp and the starch, the presence of the insoluble fibers reduces the free space in the polymer matrix reducing the $\mathrm{WVP}^{44}$. WVP is also reduced with the addition of hydrophobic polymers ${ }^{61}$. When compared to synthetic polymers, açai films had higher WVP than cellophane (0.84 x 10-10 gm-1s-1Pa-1) and low density polyethylene $(0.0036 \times 10-10 \mathrm{gm}-1 \mathrm{~s}-1 \mathrm{~Pa}-1)^{62}$.

The WVP of the açaí films limits their use to applications that require a low WVP, however, the WVP of the açaí films are inferior when compared to the other biodegradable plastics, corroborating with the studies of Soares ${ }^{63}$, regarding the improvement of the barrier properties with the addition of vegetables.

\section{Water Solubility of Films}

The solubility in water varied from 16.30 to $18.07 \%$ in the acai film, whereas for the control, it ranged from 28.18 to $36.81 \%$. Typically, polysaccharides are highly hygroscopic and disintegrate rapidly in water ${ }^{64}$, which justifies the greater solubility of the control film. The açaí pulp significantly reduced the solubility of the films ( $\mathrm{P}$ $<0.05)$. The solubility values for the açaí films were close to the cassava starch and soy protein $^{29}$ films and to the starch films added of acerola pulp at different concentrations ${ }^{8}$ where the authors verified that the higher the content of pulp added, the lower the solubility of the film. The solubility of the açaí film are even lower than the value found for biodegradable films with different fruit $\mathrm{pulps}^{65}$, which is advantageous.

High solubility does not impair film, it may be necessary in the case of films that need to be subjected to contact with water during processing of dehydrated foods. In this case, edible packagings have been used for packaging portions of ingredients to be dispersed in food mixtures, where an instant dissolution of the film in the medium is desirable ${ }^{66,8}$. Solubility is also advantageous in cases where the film is consumed along the product $^{67}$.In order to reduce water solubility, addition of hydrophobic coumponds, may reduce film hydrophilicity, resulting in an increase of water resistance ${ }^{68}$. 


\section{Mechanical Traction Tests}

Açai films showed $1.3 \pm 1.2 \mathrm{MPa}$ tensile strength at rupture, $17.74 \pm 1.4 \%$ elongation at break and $62,79 \pm 1.6 \mathrm{MPa}$ elasticity modulus. The control films presented $5.43 \pm$ $0.4 \mathrm{MPa}$ tensile strength; $0.061 \pm 0.0 \%$ elongation at break and $133.5 \pm 1.7 \mathrm{MPa}$ elasticity, indicating that addition of the açai reduced strength and increased film deformation. Analysis of variance indicated a significant difference in the parameters $(\mathrm{P}<0.05)$.

Reis et al. ${ }^{44}$ verified a reduction in tension in the starch and mango pulp films, as well as Sothornvit and Rodsamran ${ }^{69}$ who found low values for mango puree films. Rojas$\mathrm{Grau}^{70}$ found $2.90 \mathrm{MPa}$ in apple puree, alginate and glycerol films. The low tensile strength of the açaí films can be justified by the heterogeneity of the material, which makes it easier to get ruptures at these points. Dantas et al ${ }^{65}$ found lower resistance to cassava starch films and fruit pulp. Regarding the deformation, percentages were found from 14.77 to $34.78 \%$, whereas the control film presented $38.61 \%$.

The incorporation of fruits into the films alters their mechanical properties, due to the formation of a new matrix generated from interactions of the water with the fibers and the components of the matrix it self with the pulps, which increases the resistance of the packages and reduces their deformation capacity, probably due to the fiber content $^{71}$. Another explanation for the reduction of strength and elongation is that the free sugars present in fruit pulps act as plasticizers, however if the plasticizer has already been added (in adequate concentration), it can lead to a high concentration of plasticizer in the material, Resulting in excessive interaction between the polymer network and the plasticizers ${ }^{72}$ reducing the flexibility of the film. However, the açaí film presented a contrary characteristic, with a greater elongation in the rupture in the traction test in comparison to the control film, probably by the plasticizing effect of açaí components (sugars and oils) that, together with the glycerol, increased the elongation of the film.

Pure films of chitosan and hemimethylcellulose exhibited maximum elongation values of 85 and $5.14 \%$ and elasticity of 1998.1 and $808.1 \mathrm{MPa}^{73}$, respectively, that is, they were not very flexible, because the greater the elasticity, the smaller the flexibility ${ }^{74,75}$. The elasticity was higher than those found for the açaí film, indicating less stiffness which may be beneficial for some applications.

The açaí film presented superior elasticity modulus when compared to banana starch, mango and $50 \%$ glycerol films $(1.6 \text { and } 1.4 \mathrm{MPa})^{76}$ indicating that the elevation of the glycerol content promotes a reduction of the elasticity due to its capacity in reducing the interactions between the polymer chains ${ }^{57}$.

\section{CONCLUSIONS}

It was possible to elaborate films of cassava starch and lyophilized açaí with good retention of anthocyanins and considerable antioxidant activity. The material still presented a lower solubility, less water activity and a less hydrophilic surface than the control films, which guarantees a better applicability to different food types. As for the mechanical properties, the açaí film presented low tensile strength as the majority of the films added of fruit pulps, and greater elongation in relation to the control film. The film obtained besides the potential of use for packaging food, has the possibility of increasing the ingestion of anthocyanins in the diet, if consumed. 


\section{REFERENCES}

1- Campagner MR, Moris VAS, Pitombo ML, Carmo BJ, Paiva JMF. (Polymeric films based on Starch and Lignosulphonates: Preparation, Properties and Evaluation of Biodegradation). Polímeros. 2014; 24:(06) 740-751. https://dx.doi.org/10.1590/0104-1428.1700

2- Finnigan B. Barrier polymers, in: K.L. Yam (Ed.). The Wiley Encyclopedia of Packaging Technology.John Wiley and Sons, Inc. New York. 2009; p.103-109.

3- (Impact of packaging on the environment) [Internet]. Brasil: Ministério do Meio Ambiente [Acessado em: 21 Jan 2016]. Disponível em: http://www.mma.gov.br/responsabilidadesocioambiental/producao-e-consumo-sustentavel/consumo-consciente-de-embalagem/impactodas-embalagens-no-meio-ambiente

4- Bazílio FS. (Determination of the specific migration of plasticizers from di- (2-ethylhexyl) phthalate and di- (2-ethylhexyl) adipate from flexible PVC films to fatty foods: method validation and sanitary control of flexible PVC film)[Dissertação].Rio de Janeiro (RJ): Fundação Oswaldo Cruz; 2014.

5- Azeredo HMC, Faria JAF, Brito ES.(Packaging and its interactions with food).In: Azeredo, H. M. C. (Ed). Fundamentos de estabilidade de Alimentos. Brasília, DF: Embrapa. 2012; cap. 7, p. 223-250.

6- Chang YJ, Lin KL, Chang YZ. Determination of Di-(2-ethylhexyl) phthalate (DEHP) metabolites in human hair using liquid chromatography-tandem mass spectrometry. Clin. Chim. Acta. 2013; 420: 155-159.

7- (Risk in the use of PVC) [Internet]. Brasil: Instituto Brasileiro de Defesa do Consumidor[Acessado em 10 Dez 2015]. Disponível em: http://www.idec.org.br/uploads/revistas_materias/pdfs/2004-07-ed79-servico-saude.pdf

8- Farias MG, Fakhouri FM, Carvalho CWP, Ascheri JLR. (Physical-chemical characterization of edible films of added starch of acerola (Malphigia emarginatad.C.) Quím. Nova. 2012; 35: (03) 546-552.

9- Food Aditives, 21 C.R.F. Sect. 170 (2017).

10- Gutierrez TK,Tapia MS, Perez E, Fama L. Structural and mechanical properties of edible films made from native and modified cush-cush yam and cassava starch. Food Hydrocoll. 2015; 45: 211-217.

11- Reis LCB, Barcellos AD, Machado BAS, Druzian JI. (Biodegradable film incorporated with glycerol and natural additives). Cadernos de Prospecção. 2011. 4: 23-32. D.O.I.: http://dx.doi.org/10.9771/S.CPROSP.2011.004.003

12- Azeredo HMC, Mattoso LH, Wood D, Williams TG, Avena-Bustillos RJ, McHugh TH. Nanocomposite edible films from mango puree reinforced with cellulose nanofibers. $J$ Food Sci. 2009; 74: 31-35.

13- Espitia PJP, Avena-Bustillos RF, Wen-Xian Du, Teófilo RF, Soares NFF, Mc Hugh TH.Optimal antimicrobial formulation and physical-mechanical properties of edible films based on acai and pectin for food preservation. Food Pack shelf life. 2014; 2:(3) 8 - 4 .

14- Zheng W, WANG SY. Oxygen radical absorbing capacity of phenolics in blue berries, cranberries, chokeberries, and lingonberries. J. Agric Food Chem. 2003; 51: 502-509.

15- Messias KLS. (Acaitosuperfruit) [Internet]. Jaraguá do Sul (SC): Duas Rodas Industrial. [Acessado em 14 Jan 2017]. Disponível em: http://www.redejucara.org.br/apres/karina.pdf 16- Lopes TJ, Xavier M, Quadri MG, Quadri M. (Anthocyanins: a brief review of structural features and stability). R Bras Agrociência. 2007; 13: (3) 291-297.

17- Chemta F, Zill-e-huma, Khan MK. Applications of ultrasound in food technology: Processing, preservation and extraction. Ultrason Sonochem. 2011; 18: 813-835.

18- Gouvêa ACMS, et al. Identification and quantification of anthocyanins in fruits from Neomitranthes obscura (DC.) N. silveira an endemic specie from Brazil by comparison of chromatographic methodologies. Food Chem. 2015; 185, p. 277-283.

19- Santiago, M. C. P. A. (2010). (Adaptation of a high-performance liquid chromatography method for the analysis of anthocyanins in açaí juice (Euterpe oleraceae Mart.)).ISSN 01035231 Dezembro, Rio de Janeiro, RJ. 
20- ISO (International Organization for Standardization)13320-1 Particle size analysis - Laser diffraction methods - Part 1: General principles; 1999.

21- França SCA, Couto HJB. (Microgranulometric Analysis - Malvernand Sedigraph). In: Sampaio JA, França SCA, Braga PFA. Tratamento de Minérios: Práticas Laboratoriais. Rio de Janeiro: Cetem / mct; 2007. p. 101.

22- Rufino, MSM, et al. (Scientific methodology: Determination of total antioxidant activity in fruits by free radical capture ABTS). Fortaleza (CE): Embrapa; 2007 Jul. Comunicado ${ }^{\circ}$ 128. Contrato 0015279 e 506.633/2004-7. Patrocinado pelo Conselho Nacional de Desenvolvimento Científico e Tecnológico CNPq e União Européia.

23- Zuleta A, Esteve MJ, FrígolaA.ORAC and TEAC assays comparison to measure the antioxidant capacity of food products. Food Chem. 2009; 114: 310-316.

24- Re R, Pelegrine N, Proteggente A, Pannala A, Yang M, Rice-Evans C. Antioxidant activity applying an improved ABTS radical cation decolorization assay. Free Radic Biol Medic. 1999; 26 (9-10), 1231-1237.

25- Cao N, Fu Y,He J. Preparation and physical properties of soy protein isolate and gelatin composite films. Food Hydrocoll.2007; 21: 1153-1162.

26- Gontard N, Guilbert S, Cuq JL. Water and glycerol as plasticizers affect mechanical and water-vapor barrier properties of an edible wheat gluten film. J Food Sci. 1993; 58:(1) 206211.

27- American Society For Testing and Materials. Standard test method for water vapor transmission of materials.Designation E-96-90, ASTM Book of Standards, ASTM, Philadelphia.1990; 834-841.

28- Vicentini, N. M. (Elaboration and characterization of edible cassava starch films for postharvest use). [Tese].Botucatu (SP): Universidade Estadual Paulista; 2003.

29- Rocha GO, Farias MG, Carvalho CWP, Ascheri, JLR, Galdeano M C. (Biodegradable Composites Based on Cassava Starch and Soy Protein). Polímeros. 2014; 24:(05) 587-595.

30- American Society For Testing and Materials. (1993). Standard test methods for tensile properties of thin plastic sheeting, Designation D 882-91, ASTM Book of Standards, ASTM, Philadelphia, PA, p. 316.

31- Korn M, Andrade MVAS, Borges SS. (Ultrasound-Assisted Analytical Procedures). Analytica.2003; 2(3): 34-39.

32- Gordon A, et al. Chemical characterization and evaluation of antioxidant properties of Açaí fruits (Euterpe oleraceae Mart.) durin gripening. Food Chem. 2012; 133: 256-263.

33- Schauss AG, et al. Phytochemical and nutrient composition of the freeze-dried amazonian palm berry, Euterp eoleraceae Mart. (Açai). J Agr Food Chem. 2006; 54: 8598-8603.

34- Lobo ACM, Velasque LFL. Review of the literature on the therapeutic effects of açaí and Importance in food. Rev. Biosaúde. 2016; 18 (2): 97-106.

35- Malcher ESLT. (Influence of seasonality on the chemical composition and antioxidant activity of açaí (Euterpeoleracea Mart.)) [Tese]. Viçosa (MG): Universidade de Viçosa; 2011.

36- Tonon RV, Brabet C, Hubinger MD. Anthocyanin stability and antioxidant activity of spray-dried açai (Euterpe oleracea Mart.) juice produced with different carrier agents. Food Res Int. 2010;43: 907-914, 2010.

37- Reque PM, Steffensa RS, Jablonskib A, Flôresa SH, Riosa AO, Jonga EV. Cold storage of blueberry (Vaccinium spp.) fruits and juice: Anthocyanin stability and antioxidant activity. $J$ Food Compos Anal. 2014; 33: 111-116.

38- Cohen KO, Alves SM. (Acai Production System - Packaging Processing and Storage) [Internet]. Belem: Empresa brasileira de pesquisa agropeuária- Embrapa Amazônia oriental; 2006 [Acessado em: 20 Dez 2016]. Disponível em: http://sistemasdeproducao.cnptia.embrapa.br/FontesHTML/Acai/SistemaProducaoAcai_2ed/pa ginas/processamento.htm.

39- Rogez H, Pompeub DR, Akwiea SNT, Larondellec Y. Sigmoidal kinetics of anthocyanin accumulation during fruit ripening: A comparison between açaí fruits (Euterpe oleracea) and other anthocyanin-rich fruits. J Food Compos Anal. 2011; 24: 796-800

40- Bezerra TS. (Physical, chemical and morphological characterization of lyophilized marolo pulp). [Tese]. Lavras (MG): Universidade Federal de Lavras; 2014.

41- Gouvêa ACMS. (Quantification of the major acai anthocyanins of açaí by high performance liquid chromatography) [Dissertação]. Seropédica: Universidade Federal Rural do Rio de Janeiro; 2010. 
42- Cruz APG. (Evaluation of the effect of açaí extraction and microfiltration on its composition and antioxidant activity) [Dissertação]. Rio de Janeiro (RJ): Universidade Federal do Rio de Janeiro; 2008.

43- Schauss AG, et al. Antioxidant capacity and other bioactivities of the freeze-dried Amazonian Palm Berry, Euterpe oleracea, Mart. (Açai). J. Agric. Food Chem. 2006; v: 54, p. 8604-8610.

44- Reis LCB, Souza CO, Silva JBA, Martins ACM, Nunes IL, Druzian JI. Active biocomposites of cassava starch: The effectof yerba mate extract and mango pulp as antioxidant additives on the properties and the stability of a packaged product. Food and bioprod. process. 2014. Disponível em: http://dx.doi.org/10.1016/j.fbp.2014.05.004

45- Lichtenthäler R, Rodrigues RB, Maia JG, Papagiannopoulos M, Fabricius H, Marx F.Total oxidant scavenging capacities of Euterpeoleracea Mart. (Açai) fruits. Int J Food SciNutr.2005; 56: 53-/64.

46- Bartolome MM, Gomez-cordovesBC. Updated knowledge about the presence of phenolic compounds in wine.Crit. Rev. Food Sci. Nutr. 2005; 45: 85-118.

47- Escarpa A, Gonzalez MC. An overview of analytical chemistry of phenolic compounds in foods. Crit. Rev. Anal. Chem. 2001; 31: 57-139.

48- Waterschoot J, Gomand SV, Fierens E, Delcour JA. Production, structure, physicochemical and functional properties of maize, cassava, wheat, potato and rice starches. Starch/Stärke.2014; 66: 1-16.

49- De Pascual-Teresa S, Moreno DA, García-Viguera C. Flavanols and anthocyanins in cardiovascular health: a review of current evidence. Int. J. Mol. Sci. 2010; 11: 1679-703.

50- Galvano, F.; et al. Cyanidins: metabolism and biological properties. J NutrBiochem.2004; 15: 2-11.

51- Cooke D, Steward WP, Gescher AJ, Marczylo T. Anthocyans from fruits and vegetablesDoes bright colour signal cancer chemopreventive activity? Eur J Cancer.2005; 41: 19311940.

52- Tsuda TF. Dietary cyanidin 3-O- $\beta$-Dglucoside-rich purple corn color prevents obesity and ameliorates hyperglycemia in mice. $J$ Nutr.2003; 133: 2125-2130.

53- Kalt W, Forney CF, Martin A, Prior RL. Antioxidant capacity, vitamin C, phenolics, and anthocyanins after fresh storage of small fruits. J.Agr.Food Chem. 1999; 47:4638-4644.

54- Cao G, Prior RL. Comparison of different analytical methods for assessing total antioxidant capacity of human serum. Clin Chem. 1998; 44: 1309-1315.

55- Silva E, Souza J, Rogez H, Rees J-F, Larondelle Y. Antioxidant activities and polyphenolic contents of fifteen selected plant species from the Amazonian region., Food Chem. 2007; 101: 1012-1018.

56- Cerezo AB, Cuevasb E, Winterhalterb P, Garcia-Parrillaa MC, Troncos AM. Isolation, identification, and antioxidant activity of anthocyanin compounds in Camarosa strawberry. Food Chem. 2010; 123: 574-582.

57- Sothornvit R, Pitak N. Oxygen permeability and mechanical properties of banana films. Food Res Int. 2007; 40: 365-370.

58- Farias MG. (Elaboration of edible starch films with the addition of acerola pulp)[Dissertação].Seropédica: Universidade Federal Rural do Rio de Janeiro; 2011.

59- Sobral, P. J. A. (Functional properties of gelatine biofilms as a function of thickness). CiêncEngen. 1999; 8:(1) 60-67.

60- Galdeano MC, Wilhelm AE, Mali S, Grossmann MVE. Influence of Thickness on Properties of Plasticized Oat Starch Films. Braz. Arch. Biol. Technol. 2013;56 (4): 637-644.

61- Wang X,Sun X, Liu H, Li M, Ma Z. Barrier and mechanical properties of carrot puree films. Food Bioprod Process.2011; 89:149-156.

62- Melo C, Garcia PS, Grossmann MVE, Yamashita F, Dall'Antônia LH, Mali S. Properties of Extruded Xanthan-Starch-Clay Nanocomposite Films. Braz. Arch. Biol. Technol. 2011; 54 (6):1223-1333.

63- Soares NFF, Cruz RS, Viladiego AMD, et al. (Active packaging in food preservation). In: Azeredo, H. M. C. (Ed). Fundamentos de estabilidade de Alimentos. Brasília, DF: Embrapa. 2012. p. 273-275.

64- Shih, F.F. Edible films from rice protein concentrate and pullulan. Cereal Chem. 1996; 73 : (3) 406-409. 
65- Dantas EA, et al. (Characterization and evaluation of antioxidant properties of biodegradable filaments incorporated with tropical fruit pulps). Ciênc Rural. 2015; 45:(1)142148.Doi.: 10.1590/0103-8478cr20131458.

66- Ayranci E, Tunc S.A method for the measurement of the oxygen permeability and the development of edible films to reduce the rate of oxidative reactions in fresh foods. Food Chem. 2003; 80: 423.

67- Chen, H. Functional properties and applications of edible films made of milk proteins. $J$ Dairy Sci. 1995; 78: n (11) 2563-2583.

68- Ferreira FAB, Grossmann MVE, Mali S, Yamashita F, Cardoso LP. Effect of Relative Humidities on Microstructural, Barrier and Mechanical Properties of Yam StarchMonoglyceride Films. Braz. Arch. Biol. Technol. 2009; 52 (6): 1505-1512.

69- Sothornvit R, Rodsamran P. Effect of a mango film on quality of whole and minimally processed mangoes. Postharvest Biol. Technol. 2008; 47: 407.

70- Rojas-Grau, M. A.; et al.Effects of plant essential oils and oil compounds on mechanical, barrier and antimicrobial properties of alginate-apple puree edible films. J. Food Eng.2007; 81: 634.

71- Souza, C.O. etal.Mango and acerola pulps as antioxidante additives in cassava starch biobased film. J Agric Food Chem. 2011; 59: 2248-2259.

72- Arvanitoyannis, I., Psomiadou, E., Nakayama, A. Edible films made from sodium caseinate, starches, sugars orglycerol. Carbohydrat Polym.1996; 31: 179-192.

73- Rotta, J. (Physical and chemical properties of chitosan and hydroxypropylmethylcellulose forming and film solutions) [Pós-Graduação em Ciência dos Alimentos]. Santa Catarina: Universidade Federal de Santa Catarina; 2008.

74- Canevarolo JR, Sebastião V. (Science of polymers). 1 ed. Artliber Editora. São Carlos; 2002.

75- Lucas EF, Soares BG, Monteiro E. (Characterization of polymers molecular weight determination and thermal analysis); Ed. Rio de Janeiro, E-papers serviços editoriais; 2001.

76- Romero-Bastida CA, Bello-Pérez LA, García MA, Martino MN, Solorza-Feria J, Zaritzk NE. Physicochemical and microstructural characterization of films prepared by thermal and cold gelatinization from non-conventional sources of starches. Carbohydrat Polym.2005;60: 235-244 